\title{
Socioeconomic status and prostate cancer incidence and mortality rates among the diverse population of California
}

\author{
Iona Cheng $\cdot$ John S. Witte $\cdot$ Laura A. McClure \\ Sarah J. Shema $\cdot$ Myles G. Cockburn · \\ Esther M. John · Christina A. Clarke
}

Received: 30 September 2008/Accepted: 25 May 2009/Published online: 13 June 2009

(c) The Author(s) 2009. This article is published with open access at Springerlink.com

\begin{abstract}
Background The racial/ethnic disparities in prostate cancer rates are well documented, with the highest incidence and mortality rates observed among African-Americans followed by non-Hispanic Whites, Hispanics, and Asian/ Pacific Islanders. Whether socioeconomic status (SES) can account for these differences in risk has been investigated in previous studies, but with conflicting results. Furthermore, previous studies have focused primarily on the differences between African-Americans and non-Hispanic Whites, and little is known for Hispanics and Asian/Pacific Islanders. Objective To further investigate the relationship between SES and prostate cancer among African-Americans, non-
\end{abstract}

Electronic supplementary material The online version of this article (doi:10.1007/s10552-009-9369-0) contains supplementary material, which is available to authorized users.

I. Cheng $(\bowtie)$ J. S. Witte

Department of Epidemiology and Biostatistics and Institute for Human Genetics, University of California, San Francisco, San Francisco, CA 94143-0794, USA

e-mail: chengi@humgen.ucsf.edu

I. Cheng

Epidemiology Program, Cancer Research Center of Hawaii, University of Hawaii, Honolulu, HI 96813, USA

L. A. McClure - S. J. Shema - E. M. John - C. A. Clarke Northern California Cancer Center, Fremont, CA 94538, USA

M. G. Cockburn

Department of Preventive Medicine, Norris Comprehensive Cancer Center, Keck School of Medicine, University of Southern California, Los Angeles, CA 90089, USA

E. M. John · C. A. Clarke

Department of Health Research \& Policy, Stanford Cancer

Center, Stanford School of Medicine, Palo Alto, CA 94301, USA
Hispanic Whites, Hispanics, and Asian/Pacific Islanders, we conducted a large population-based cross-sectional study of 98,484 incident prostate cancer cases and 8,997 prostate cancer deaths from California.

Methods Data were abstracted from the California Cancer Registry, a population-based surveillance, epidemiology, and end results (SEER) registry. Each prostate cancer case and death was assigned a multidimensional neighborhood-SES index using the 2000 US Census data. SES quintile-specific prostate cancer incidence and mortality rates and rate ratios were estimated using SEER*Stat for each race/ethnicity categorized into 10-year age groups.

Results For prostate cancer incidence, we observed higher levels of SES to be significantly associated with increased risk of disease [SES Q1 vs. Q5: relative risk $(\mathrm{RR})=1.28$; 95\% confidence interval (CI): 1.25-1.30]. Among younger men (45-64 years), African-Americans had the highest incidence rates followed by non-Hispanic Whites, Hispanics, and Asian/Pacific Islanders for all SES levels. Yet, among older men (75-84 years) Hispanics, following African-Americans, displayed the second highest incidence rates of prostate cancer. For prostate cancer deaths, higher levels of SES were associated with lower mortality rates of prostate cancer deaths (SES Q1 vs. Q5: RR $=0.88$; 95\% CI: 0.92-0.94). African-Americans had a twofold to fivefold increased risk of prostate cancer deaths in comparison to non-Hispanic Whites across all levels of SES.

Conclusions Our findings suggest that SES alone cannot account for the greater burden of prostate cancer among African-American men. In addition, incidence and mortality rates of prostate cancer display different age and racial/ethnic patterns across gradients of SES.

Keywords Prostate cancer - Socioeconomic status Disparities · Incidence rates $\cdot$ Mortality rates 


\section{Introduction}

Prostate cancer is one of the leading causes of cancer morbidity and mortality among men in the US with 186,320 new cases and 28,660 deaths estimated for 2008 [1]. Striking features of prostate cancer are the pronounced racial/ethnic disparities in incidence and mortality rates. African-Americans experience the highest burden of the disease followed by non-Hispanic Whites, Hispanics, and Asian/Pacific Islanders [2]. Reasons for these racial/ethnic disparities remain poorly understood and are likely due to the interplay of social, environmental, and genetic factors. To better understand the interaction of these factors, the relative contribution of each domain must be thoroughly evaluated in relation to the disparity in rates of prostate cancer.

Socioeconomic status (SES) is linked to several factors that may collectively influence the burden of prostate cancer, including lifestyle and environmental risk factors as well as access, quality, and utilization of screening and health care services $[3,4]$. In the years following adoption of prostate specific antigen (PSA) screening for prostate cancer, most studies reported associations between prostate cancer and higher levels of SES [5-9]. However, inconsistent associations have been reported for different racial/ ethnic groups [10, 11]. Specifically, a large national US study reported higher SES to be associated with increased incidence of prostate cancer among non-Hispanic Whites, but not among Hispanics or African-Americans [11]; whereas a study of men in the San Francisco Bay Area observed a positive relationship with SES among Asian/ Pacific Islanders and Hispanics but not among non-Hispanic Whites and African-Americans [10]. Less controversial are associations of higher SES with lower mortality rates of prostate cancer, which have been documented in multiple studies [12-17].

It remains poorly understood whether SES may account for the substantial racial/ethnic disparities in prostate cancer incidence and mortality among men in the US. Previous studies have largely focused on explaining differences between African-Americans and Whites without consideration of other racial/ethnic groups. These studies generally agree that SES does not entirely explain racial/ethnic differences in prostate cancer incidence [5, 10, 18]. However, findings have been mixed regarding the contribution of SES to survival differences between racial/ethnic groups [13-17, 19-21].

To further clarify the relationship between SES, race/ ethnicity, and prostate cancer incidence and mortality, we studied a population-based series of prostate cancer patients with large numbers of African-Americans, nonHispanic Whites, Hispanics, and Asian/Pacific Islanders for whom small area-level SES information was available.

\section{Materials and methods}

Prostate cancer patients

We obtained from the California Cancer Registry (CCR), comprising three of the National Cancer Institute's surveillance, epidemiology, end results (SEER) program registries, data regarding all 102,691 incident cases of invasive prostate cancer (as mandated by state law) and 9,029 prostate cancer deaths reported for two time periods: 1 January 1998 to 31 December 2002 and 1 January 1999 to 31 December 2001 ["International Classification of Diseases for Oncology, Second Edition" (Percy, ICD-0, 1990) site code C619]. These 5-year (incidence) and 3-year (mortality) pericensal periods were chosen because the appropriate census block group-level denominators needed for neighborhood SES rate calculations were available for the 2000 census. Information regarding patient age at cancer diagnosis, race/ethnicity, residential address at diagnosis, and tumor stage and grade was abstracted directly from the medical record. Information regarding prostate cancer deaths, including age, race/ethnicity, and residential address at death, was obtained from death certificates. Race/ethnicity was classified as the following mutually exclusive racial/ethnic groups: African-American, Asian/Pacific Islander, Hispanic (of any race), non-Hispanic White, and other/unknown. We defined nonaggressive disease as tumors that were confined to the prostate and were either well or moderately differentiated. Regional and distant tumors or localized tumors that were poorly differentiated or undifferentiated were classified as aggressive disease. There were 9,712 tumors $(9.9 \%)$ missing stage or grade information; these tumors were included in all analyses except for stratified analysis by aggressiveness of disease.

We restricted the present study to men aged 45 years and older at diagnosis or death due to prostate cancer, who were of known race/ethnicity. Men aged $\leq 45$ years (456 incident cases and 14 deaths) were excluded from analysis due to small numbers as well as those with unknown race/ethnicity (3,751 incident cases and 18 deaths), resulting in a final study population to 98,484 incident prostate cancer cases and 8,997 prostate cancer deaths.

Socioeconomic status and population data

Individual-level SES characteristics (e.g., education, income, and occupation) are not routinely collected by most US cancer registries, including the CCR. However, patient residential address at diagnosis is routinely geocoded by the CCR, and address at death was obtained from California death certificate files. Residential addresses were linked to neighborhood-level SES characteristics from the 
US Census Bureau. Census block group (an area containing on average 1,500 residents) was the smallest geographic census unit having information on both SES characteristics and population counts in which we were able to estimate incidence and mortality rates for the decennial census. Patients for whom block group of residence was unknown (incident cases: $n=5,139,5.2 \%$; deaths; $n=253 ; 2.8 \%$ ) were randomly allocated to block groups within the same county. Patients with unknown block group did not differ significantly $(p \leq 0.05)$ from patients with known block group on tumor characteristics of stage and grade.

We used a previously developed method [22] to assign a single measure of SES to each California census block group for the time periods in question. Cases diagnosed from 1998-2002 and prostate cancer deaths from 19912001 were linked to 2000 census data. Principal component analysis was used to develop a single SES index from seven census-based indicator variables of SES: mean years of education; median household income; percent living $200 \%$ below poverty level; percent blue-collar workers; percent older than 16 years in workforce without job; median rent; and median house value [22]. Thus, this index incorporates three critical domains of SES-education, income, and occupation [23]. This index was used to assign a standardized score to each block group, which was then categorized into quintile levels. For each SES quintile, "Supplementary Table 1" shows the distribution of the seven census-based indicator variables of SES and the racial/ethnic distribution among the state of California. Hispanics comprised the largest proportion of subjects for SES quintiles 1 and 2, while non-Hispanic Whites were the largest group for quintiles 3-5. For use as denominators in rate calculation, we obtained population data from age-, sex-, and race-specific population counts for census block groups from the modified age, race, sex, and Hispanic origin ("MARS") files from the 2000 US census. Because population estimates for census block groups were not available for intercensal years, we multiplied the 2000 population counts by five and three, respectively, to estimate the total population at risk for the 5-year period of incidence and 3-year period of mortality.

\section{Statistical analysis}

Case counts and population estimates were stratified by 10 year age groups, race/ethnicity, and neighborhood SES quintile. Prostate cancer incidence and mortality rates were calculated per 100,000 individuals. SES quintile-specific incidence and mortality rate ratios (RR) and 95\% confidence intervals (CI) were estimated and when appropriate age adjusted to the 2000 US standard population using SEER*Stat, version 6.3.4.

\section{Results}

Socioeconomic status and prostate cancer incidence

For 98,484 incident cases of prostate cancer, the distribution of race/ethnicity, stage, grade, and neighborhood SES quintile varied by 10-year age group (Table 1). Non-Hispanic Whites represented over $68 \%$ of all cases across all age groups. African-Americans cases were the second largest racial/ethnic group (15\%) among the youngest age group (45-54 years) but the smallest group (6\%) among the oldest age group (85+ years). Hispanics and Asian/ Pacific Islanders represented $10-14 \%$ and $4-7 \%$ of the cases, respectively, across the 10-year age groups. The majority of cases was of a nonaggressive type, localized disease, and moderately differentiated.

Higher incidence rates of prostate cancer were associated with increasing levels of SES across all racial/ethnic groups (Table 2). Among all racial/ethnic groups combined, those at the highest quintile of SES had a $28 \%$ higher incidence rate of prostate cancer than those in the lowest quintile (95\% CI: 1.25-1.30). The largest difference in SES-specific rates was observed among Hispanics, with an incidence rate of prostate cancer that was $80 \%$ higher among men in the highest quintile of SES in comparison to those in the lowest SES quintile (95\% CI: 1.68-1.92). In a stratified analysis by severity of disease, a similar pattern was observed for both nonaggressive and aggressive disease such that significantly higher rates of prostate cancer were observed with increasing gradients of SES (Table 2). In particular, for men with aggressive disease those at the highest quintile of SES had a 1.2-fold significant increased risk of prostate cancer than those at the lowest SES quintile. This same pattern was seen for all four racial/ethnic groups.

In contrast to the expected exponential increase in prostate cancer incidence with age [24], for all SES levels a peak in incidence rate was seen for African-Americans and non-Hispanic Whites at 65-74 years of age, while for Hispanics and Asians/Pacific Islanders incidence rates peaked at 75-84 years (Table 3). Furthermore, different racial/ethnic-specific patterns in incidence rates were seen for younger and older age groups. Specifically, among younger men aged 45-64 years, African-Americans had the highest incidence rates followed by non-Hispanic Whites, Hispanics, and Asians for each level of SES. Most notably, African-Americans (45-64 years) had a significant twofold higher incidence rate of prostate cancer in comparison to non-Hispanic Whites, irrespective of SES. Among older men aged 75-84 years, Hispanics, following African-Americans, had the second highest incidence rates of prostate cancer across all SES quintiles, while nonHispanics Whites and Asians had the lowest incidence 
Table 1 Characteristics of incident prostate cancer cases by 10-year age groups, California, 1998-2002 $(n=98,484)$

\begin{tabular}{|c|c|c|c|c|c|}
\hline Years & $45-54$ & $55-64$ & $65-74$ & $75-84$ & $85+$ \\
\hline Number & 7,374 & 25,712 & 38,206 & 22,390 & 4,802 \\
\hline \multicolumn{6}{|l|}{ Race/ethnicity, $n(\%)$} \\
\hline Non-Hispanic White & 4,986 (67.6) & $18,035(70.1)$ & $26,958(70.6)$ & $16,694(74.6)$ & $3,719(77.4)$ \\
\hline African-American & $1,101(14.9)$ & $3,065(11.9)$ & $3,203(8.4)$ & $1,362(6.1)$ & $290(6.0)$ \\
\hline Hispanic & $979(13.3)$ & $3,340(13.0)$ & $5,393(14.1)$ & 2,675 (11.9) & $497(10.3)$ \\
\hline Asian/Pacific Islander & $308(4.2)$ & $1,275(5.0)$ & $2,652(6.9)$ & $1,659(7.4)$ & $296(6.2)$ \\
\hline \multicolumn{6}{|l|}{ Severity, $n(\%)^{\mathrm{a}}$} \\
\hline Non-aggressive & $5,272(74.8)$ & $18,292(74.6)$ & $26,399(73.8)$ & $13,300(69.6)$ & $1,511(53.8)$ \\
\hline Aggressive & $1,775(25.2)$ & $6,241(25.4)$ & 9,391 (26.2) & $5,805(30.4)$ & $1,295(46.1)$ \\
\hline \multicolumn{6}{|l|}{ Stage, $n(\%)^{\mathrm{a}}$} \\
\hline Localized & $6,089(84.3)$ & $21,530(85.7)$ & $32,484(88.0)$ & $17,638(87.0)$ & $2,520(74.9)$ \\
\hline Regional/distant & $1,136(15.7)$ & $3,593(14.3)$ & $4,442(12.0)$ & $2,625(13.0)$ & $846(25.1)$ \\
\hline \multicolumn{6}{|l|}{ Grade, $n(\%)^{\mathrm{a}}$} \\
\hline Well differentiated; I & $244(3.4)$ & $1,022(4.1)$ & $1,887(5.1)$ & $1,228(6.1)$ & $190(6.2)$ \\
\hline Moderately differentiated; II & $5,758(80.5)$ & $19,673(78.8)$ & $27,205(74.2)$ & $13,548(67.2)$ & $1,595(52.0)$ \\
\hline Poorly/undifferentiated; III/IV & $1,155(16.1)$ & $4,277(17.1)$ & $7,565(20.6)$ & $5,375(26.7)$ & $1,281(41.2)$ \\
\hline \multicolumn{6}{|l|}{ Socioeconomic status quintile, $n(\%)$} \\
\hline Q1 & $771(10.5)$ & $2,916(11.3)$ & $4,855(12.7)$ & $2,926(13.1)$ & $690(14.4)$ \\
\hline Q2 & $1,121(15.2)$ & $4,040(15.7)$ & $6,482(17.0)$ & $4,025(18.0)$ & $944(19.7)$ \\
\hline Q3 & $1,527(20.7)$ & $5,085(19.8)$ & $7,962(20.8)$ & $4,674(20.9)$ & $1,008(21.0)$ \\
\hline Q4 & $1,780(24.1)$ & $5,650(22.0)$ & $8,496(22.2)$ & $4,991(22.3)$ & $1,074(22.3)$ \\
\hline Q5 & $2,175(29.5)$ & $8,021(31.2)$ & $10,411(27.2)$ & $5,774(25.8)$ & $1,086(22.6)$ \\
\hline
\end{tabular}

${ }^{\text {a }}$ Numbers do not add up to 98,484 due to missing data

rates. This pattern was similar among men aged $\geq 85$ years with the exception of those at the lowest SES level. For aggressive prostate cancer, incidence rates were highest for African-Americans in all age groups and were twofold to threefold higher than the rates of non-Hispanic Whites among men aged 45-64 years (see "Supplementary Table 2"). Among men aged 65-84 years, higher incidence rates were also noted in Hispanic men, with rates between those of African-Americans and non-Hispanics and Whites, particularly among those at higher SES levels (Q3, Q4, and Q5) (see "Supplementary Table 2").

Socioeconomic status and prostate cancer mortality

Table 4 shows distributions of the 8,997 prostate cancer deaths by race/ethnicity and SES. Non-Hispanic Whites comprised the majority (55 to $79 \%$ ) of deaths in all age groups. SES and prostate cancer mortality rates were inversely associated with decreasing mortality rates seen with increasing levels of SES (Table 5). Men at the highest quintile of SES had a $12 \%$ significant reduction in risk of prostate cancer death compared to men at the lowest SES quintile $(\mathrm{RR}=0.88 ; 95 \% \mathrm{CI}: 0.82-0.94)$. Although within each racial/ethnic group there were no significant differences in mortality rates across levels of SES, non-Hispanic
Whites demonstrated a trend of lower morality rates associated with higher SES levels (Table 5).

Table 6 displays the racial/ethnic-specific patterns of prostate cancer mortality rates across SES levels by 10 year age groups. Across all age groups, African-Americans had the highest mortality rates of prostate cancer for all quintiles of SES, with mortality rates that were twofold to fivefold higher than those of non-Hispanics Whites. Asian/ Pacific Islanders had the lowest rates of prostate cancer mortality for all SES quintiles that were generally less than half that of the rates of non-Hispanic Whites. In most age and SES groups, Hispanics had slightly lower mortality rates than non-Hispanic Whites.

\section{Discussion}

In this large multiethnic population, population-based series of prostate cancer patients, increasing levels of SES were associated with higher incidence and lower mortality rates of prostate cancer. Furthermore, across all levels of SES, African-Americans had a substantially larger burden of prostate cancer deaths than other racial/ethnic groups, suggesting that SES alone cannot entirely account for the racial/ethnic differences in prostate cancer mortality. 
Table 2 Prostate cancer (PCa) incidence rates (per 100,000) among men 45 years and older by SES and race/ethnicity, California 1998-2002

\begin{tabular}{|c|c|c|c|c|c|c|c|c|c|c|}
\hline & \multirow[t]{2}{*}{ SES } & \multicolumn{3}{|c|}{ Total PCa } & \multicolumn{3}{|c|}{ Localized PCa } & \multicolumn{3}{|c|}{ Aggressive $\mathrm{PCa}$} \\
\hline & & $n$ & Rate & RR $(95 \%$ CI $)$ & $n$ & Rate & RR $(95 \%$ CI $)$ & $n$ & Rate & RR $(95 \%$ CI $)$ \\
\hline \multirow[t]{5}{*}{ All } & Q1 & 12,158 & 411.7 & 1.00 & 7,383 & 84.4 & 1.00 & 3,177 & 37.3 & 1.00 \\
\hline & Q2 & 16,612 & 401.1 & $0.97(0.95-1.00)$ & 10,501 & 86.7 & $1.03(1.00-1.06)$ & 4,371 & 36.7 & $0.98(0.94-1.04)$ \\
\hline & Q3 & 20,256 & 434.0 & $1.05(1.03-1.08)$ & 13,359 & 98.1 & $1.16(1.13-1.20)$ & 4,991 & 37.3 & $1.00(0.96-1.05)$ \\
\hline & Q4 & 21,991 & 455.6 & $1.11(1.08-1.13)$ & 14,783 & 104.9 & $1.24(1.21-1.28)$ & 5,451 & 39.4 & $1.06(1.01-1.11)$ \\
\hline & Q5 & 27,467 & 525.5 & $1.28(1.25-1.30)$ & 19,044 & 124.3 & $1.47(1.43-1.51)$ & 6,633 & 44.7 & $1.20(1.15-1.25)$ \\
\hline \multirow[t]{5}{*}{ Non-Hispanic White } & Q1 & 4,788 & 441.6 & 1.00 & 2,960 & 94.8 & 1.00 & 1,199 & 38.6 & 1.00 \\
\hline & Q2 & 10,251 & 399.8 & $0.91(0.87-0.94)$ & 6,546 & 88.6 & $0.93(0.89-0.98)$ & 2,640 & 36.0 & $0.93(0.87-1.00)$ \\
\hline & Q3 & 14,744 & 435.5 & $0.99(0.95-1.02)$ & 9,833 & 100.6 & $1.06(1.02-1.11)$ & 3,491 & 36.0 & $0.93(0.87-1.00)$ \\
\hline & Q4 & 17,115 & 460.4 & $1.04(1.01-1.08)$ & 11,630 & 108.0 & $1.14(1.10-1.19)$ & 4,112 & 38.6 & $1.00(0.94-1.07)$ \\
\hline & Q5 & 23,494 & 545.4 & $1.24(1.20-1.27)$ & 16,397 & 130.5 & $1.38(1.32-1.43)$ & 5,538 & 45.2 & $1.17(1.10-1.25)$ \\
\hline \multirow[t]{5}{*}{ African-American } & Q1 & 2,710 & 711.3 & 1.00 & 1,599 & 142.0 & 1.00 & 697 & 63.5 & 1.00 \\
\hline & Q2 & 2,165 & 702.7 & $0.99(0.93-1.05)$ & 1,350 & 146.3 & $1.03(0.96-1.11)$ & 583 & 65.6 & $1.03(0.92-1.16)$ \\
\hline & Q3 & 1,776 & 738.7 & $1.04(0.97-1.11)$ & 1,180 & 162.9 & $1.15(1.06-1.24)$ & 439 & 62.8 & $0.99(0.87-1.13)$ \\
\hline & Q4 & 1,500 & 798.1 & $1.12(1.05-1.20)$ & 1,006 & 176.7 & $1.24(1.14-1.36)$ & 386 & 70.5 & $1.11(0.97-1.28)$ \\
\hline & Q5 & 867 & 933.7 & $1.31(1.22-1.43)$ & 614 & 219.5 & $1.55(1.40-1.71)$ & 220 & 85.1 & $1.34(1.13-1.60)$ \\
\hline \multirow[t]{5}{*}{ Hispanic } & Q1 & 3,946 & 348.7 & 1.00 & 2,407 & 70.4 & 1.00 & 30 & 32.0 & 1.00 \\
\hline & Q2 & 3,147 & 393.1 & $1.13(1.07-1.19)$ & 1,950 & 80.6 & $1.15(1.07-1.22)$ & 34.1 & 36.6 & $1.14(1.04-1.26)$ \\
\hline & Q3 & 2,511 & 440.7 & $1.26(1.20-1.33)$ & 1,595 & 93.7 & $1.33(1.24-1.43)$ & 37.4 & 40.5 & $1.27(1.14-1.41)$ \\
\hline & Q4 & 1,837 & 471.0 & $1.35(1.27-1.43)$ & 1,179 & 99.8 & $1.42(1.32-1.53)$ & 41.1 & 45.2 & $1.41(1.26-1.59)$ \\
\hline & Q5 & 1,443 & 625.9 & $1.80(1.68-1.92)$ & 967 & 139.1 & $1.98(1.82-2.14)$ & 53.2 & 59.3 & $1.85(1.63-2.11)$ \\
\hline \multirow[t]{5}{*}{ Asian/Pacific Islander } & Q1 & 714 & 234.3 & 1.00 & 417 & 47.1 & 1.00 & 208 & 24.0 & 1.00 \\
\hline & Q2 & 1,049 & 242.6 & $1.04(0.94-1.14)$ & 655 & 51.9 & $1.10(0.97-1.25)$ & 282 & 22.5 & $0.94(0.78-1.14)$ \\
\hline & Q3 & 1,225 & 278.1 & $1.19(1.08-1.31)$ & 751 & 57.8 & $1.23(1.09-1.39)$ & 385 & 30.4 & $1.27(1.07-1.52)$ \\
\hline & Q4 & 1,539 & 306.5 & $1.31(1.19-1.43)$ & 968 & 64.1 & $1.36(1.21-1.53)$ & 443 & 31.4 & $1.31(1.11-1.56)$ \\
\hline & Q5 & 1,663 & 297.4 & $1.27(1.16-1.39)$ & 1,066 & 62.9 & $1.33(1.19-1.50)$ & 487 & 31.4 & $1.31(1.11-1.56)$ \\
\hline
\end{tabular}

Age-adjusted to the 2000 US standard population

The elevated incidence rate of prostate cancer associated with higher levels of SES is likely attributable at least in some part to variation in access and utilization of health services; in particular, prostate cancer screening through PSA testing. PSA testing greatly increases the detection of prostate tumors, which leads at the population-level to elevated incidence rates of prostate cancer. Studies have reported that men at higher levels of SES are more likely to undergo PSA testing $[25,26]$, ultimately influencing the amount of disease in the population. The peak in incidence rates of prostate cancer among non-Hispanics Whites and African-Americans at 65-74 years of ages are in agreement with previous SEER reports [2] and may reflect heavier screening practices at earlier ages, while the later peak among Hispanics and Asian/Pacific Islanders at 7584 years may reflect later adoption and lower utilization of PSA screening. Prior research has shown that Asians and Hispanics are less likely to receive physician discussions of PSA testing than higher risk Whites and African-Americans [27].
A consistent racial/ethnic-specific pattern of incidence rates across SES levels was observed only among younger adult men $(<65$ years). To our knowledge, our findings of an increased incidence of prostate cancer among older Hispanics (75-85 years) at the higher levels of SES relative to non-Hispanic Whites have not been reported previously. In a national study of cancer among US Hispanics, Howe et al. [11] reported that Hispanics are less likely to have health care coverage than non-Hispanics Whites, especially among those younger than 65 years. With more health care coverage for older Hispanics and better resources for those at higher levels of SES, such men may have improved access and utilization of screening services that otherwise may have not been available-this may account for the higher incidence rates among this particular group of Hispanics. Our findings are in line with two similar yet smaller studies in Los Angeles [5] and the San Francisco Bay Area [10] in which across all levels of SES a similar racial/ethnic-specific pattern in age-adjusted incidence rates were seen with the exception of greater 


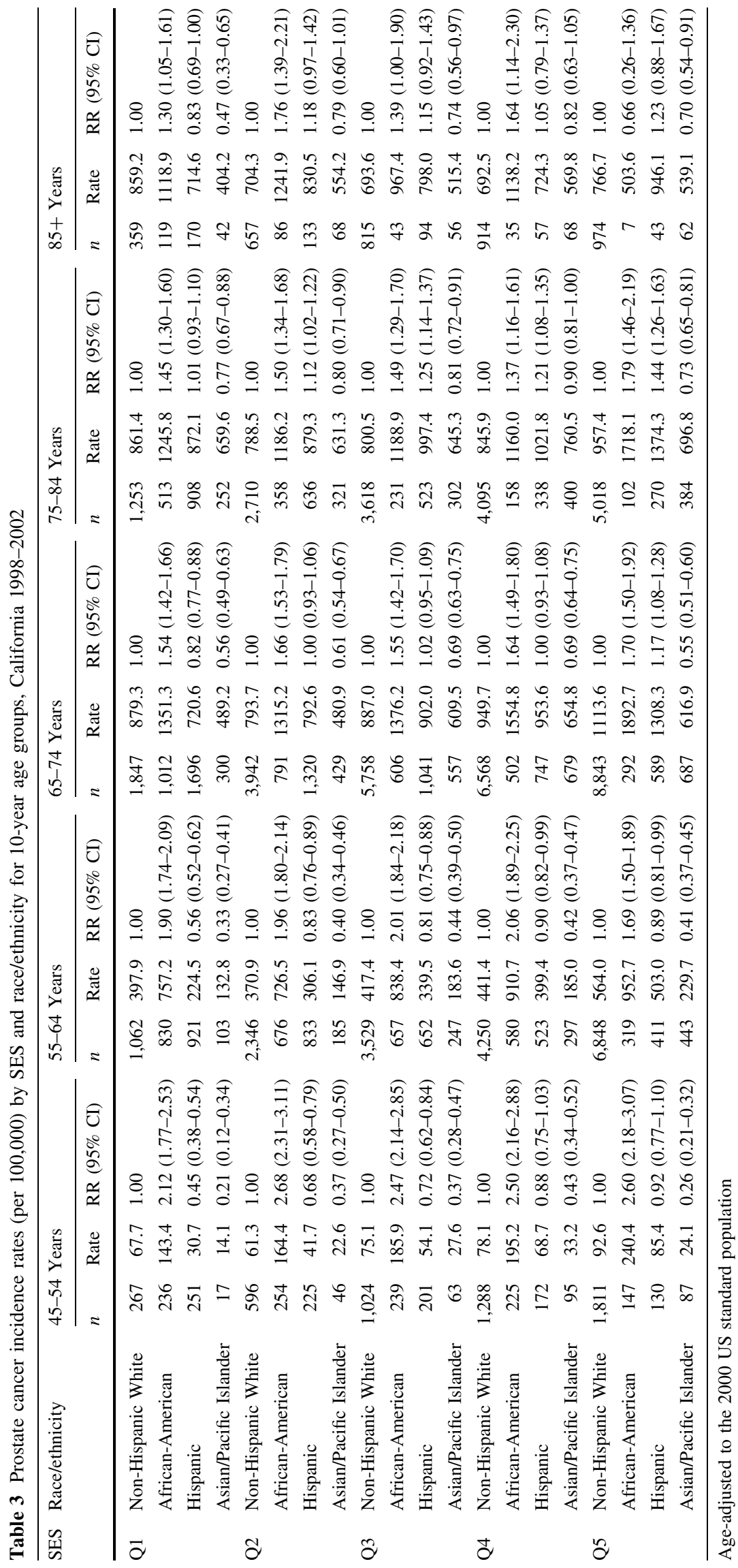


Table 4 Characteristics of prostate cancer deaths by 10-year age groups, California, 1999-2001 $(n=8,997)$

\begin{tabular}{|c|c|c|c|c|c|}
\hline Years & $45-54$ & $55-64$ & $65-74$ & $75-84$ & $85+$ \\
\hline Number & 125 & 596 & 1910 & 3787 & 2579 \\
\hline \multicolumn{6}{|l|}{ Race/ethnicity, $n(\%)$} \\
\hline Non-Hispanic White & $69(55.2)$ & $397(66.6)$ & $1,291(67.6)$ & $2,887(76.2)$ & $2044(79.3)$ \\
\hline African-American & $29(23.2)$ & $112(18.8)$ & $289(15.1)$ & $367(9.7)$ & $185(7.2)$ \\
\hline Hispanic & $25(20.0)$ & $74(12.4)$ & $276(14.5)$ & $367(9.7)$ & $211(8.2)$ \\
\hline Asian/Pacific Islander & $2(1.6)$ & $13(2.2)$ & $54(2.8)$ & $166(4.4)$ & $139(5.4)$ \\
\hline \multicolumn{6}{|c|}{ Socioeconomic status quintile, $n(\%)$} \\
\hline Q1 & $24(19.2)$ & $94(15.8)$ & $315(16.5)$ & $527(13.9)$ & $345(13.4)$ \\
\hline Q2 & $27(21.6)$ & $147(24.7)$ & $408(21.4)$ & $735(19.4)$ & $527(20.4)$ \\
\hline Q3 & $26(20.8)$ & $131(22.0)$ & $414(21.7)$ & $870(23.0)$ & $560(21.7)$ \\
\hline Q4 & $25(20.0)$ & $126(21.1)$ & $382(20.0)$ & $870(23.0)$ & $572(22.2)$ \\
\hline Q5 & $23(18.4)$ & 98 (16.4) & $391(20.5)$ & $785(20.7)$ & $575(22.3)$ \\
\hline
\end{tabular}

Table 5 Prostate cancer mortality rates (per 100,000) among men 45 years and older by SES and race/ethnicity, California 1999-2001

\begin{tabular}{|c|c|c|c|c|c|c|c|c|c|c|c|c|c|c|c|}
\hline \multirow[t]{2}{*}{ SES } & \multicolumn{3}{|l|}{ All } & \multicolumn{3}{|c|}{ Non-Hispanic White } & \multicolumn{3}{|c|}{ African-American } & \multicolumn{3}{|c|}{ Hispanic } & \multicolumn{3}{|c|}{ Asian/Pacific Islander } \\
\hline & $n$ & Rate & RR (95\% CI) & $n$ & Rate & RR (95\% CI) & $n$ & Rate & RR $(95 \%$ CI $)$ & $n$ & Rate & RR $(95 \% \mathrm{CI})$ & $n$ & Rate & $\mathrm{RR}(95 \% \mathrm{CI})$ \\
\hline Q1 & 1,305 & 33.5 & 1.00 & 559 & 33.1 & 1.00 & 355 & 67.6 & 1.00 & 338 & 27.3 & 1.00 & 53 & 13.9 & 1.00 \\
\hline Q2 & 1,844 & 32.5 & $\begin{array}{l}0.97 \\
\quad(0.90-1.04)\end{array}$ & 1,254 & 32.6 & $\begin{array}{l}0.99 \\
\quad(0.89-1.09)\end{array}$ & 254 & 64.8 & $\begin{array}{l}0.96 \\
\quad(0.81-1.13)\end{array}$ & 243 & 27.1 & $\begin{array}{l}0.99 \\
\quad(0.83-1.18)\end{array}$ & 93 & 19.3 & $\begin{array}{l}1.38 \\
\quad(0.97-1.99)\end{array}$ \\
\hline Q3 & 2,001 & 31.0 & $\begin{array}{l}0.93 \\
\quad(0.86-0.99)^{\mathrm{a}}\end{array}$ & 1,576 & 31.4 & $\begin{array}{l}0.95 \\
\quad(0.86-1.05)\end{array}$ & 176 & 64.7 & $\begin{array}{l}0.96 \\
\quad(0.79-1.15)\end{array}$ & 177 & 27.9 & $\begin{array}{l}1.02 \\
\quad(0.84-1.24)\end{array}$ & 72 & 15.1 & $\begin{array}{l}1.09 \\
\quad(0.74-1.59)\end{array}$ \\
\hline Q4 & 1,975 & 29.6 & $\begin{array}{l}0.88 \\
\quad(0.82-0.95)^{\mathrm{a}}\end{array}$ & 1,635 & 29.9 & $\begin{array}{l}0.91 \\
\quad(0.82-1.00)\end{array}$ & 134 & 72.5 & $\begin{array}{l}1.07 \\
\quad(0.87-1.32)\end{array}$ & 123 & 27.9 & $\begin{array}{l}1.02 \\
\quad(0.82-1.27)\end{array}$ & 83 & 15.9 & $\begin{array}{l}1.14 \\
\quad(0.79-1.65)\end{array}$ \\
\hline Q5 & 1,872 & 29.5 & $\begin{array}{l}0.88 \\
\quad(0.82-0.94)^{\mathrm{a}}\end{array}$ & 1,664 & 30.7 & $\begin{array}{l}0.93 \\
\quad(0.84-1.02)\end{array}$ & 63 & 73.5 & $\begin{array}{l}1.09 \\
\quad(0.81-1.44)\end{array}$ & 72 & 27.8 & $\begin{array}{l}1.02 \\
\quad(0.77-1.33)\end{array}$ & 73 & 14.0 & $\begin{array}{l}1.01 \\
\quad(0.69-1.47)\end{array}$ \\
\hline
\end{tabular}

Age-adjusted to the 2000 US standard population

a The overall lower mortality rate in comparison with racial/ethnic specific rates is attributed to non-Hispanic Whites and Asian/Pacific Islanders having larger population denominators at the higher SES levels in comparison with lower SES levels with Blacks and Hispanics having larger population denominators at lower SES levels in comparison

incidence of prostate cancer among Hispanics than that of Whites for those at the higher levels of SES. Age-stratified effects as shown in our study were not examined in these previous reports $[5,10]$.

Because screening practices greatly influence the incidence rates of prostate cancer, we also examined mortality as it may serve as a better index of risk across groups and may reflect the most clinically relevant forms of disease. The lower mortality rates of prostate cancer seen with higher levels of SES are likely attributed to factors linked to a better health status by affording optimal use of medical services such as early detection and treatment regimens, acquiring pertinent health information and education, and avoiding high risk health behaviors [15]. This overall inverse association between mortality and SES was largely driven by non-Hispanics Whites with the remaining racial/ ethnic groups demonstrating no association. This could be explained due to insufficient power among the remaining racial/ethnic groups given their smaller numbers of deaths and fewer overall Census numbers at higher levels of SES. In addition, this could be due to inadequacy of our SES index in capturing SES parameters that are most relevant for certain non-White racial/ethnic groups (discussed below). Lastly, these findings may suggest that SES does not play a role in prostate cancer mortality among AfricanAmericans, Hispanics, and Asian/Pacific Islanders.

For every level of SES, African-Americans had the highest burden of prostate cancer deaths in comparison to other three racial/ethnic groups. These findings are in agreement with three previous studies that reported that the measures of SES cannot account for the differences in mortality/survival between African-Americans and Whites 


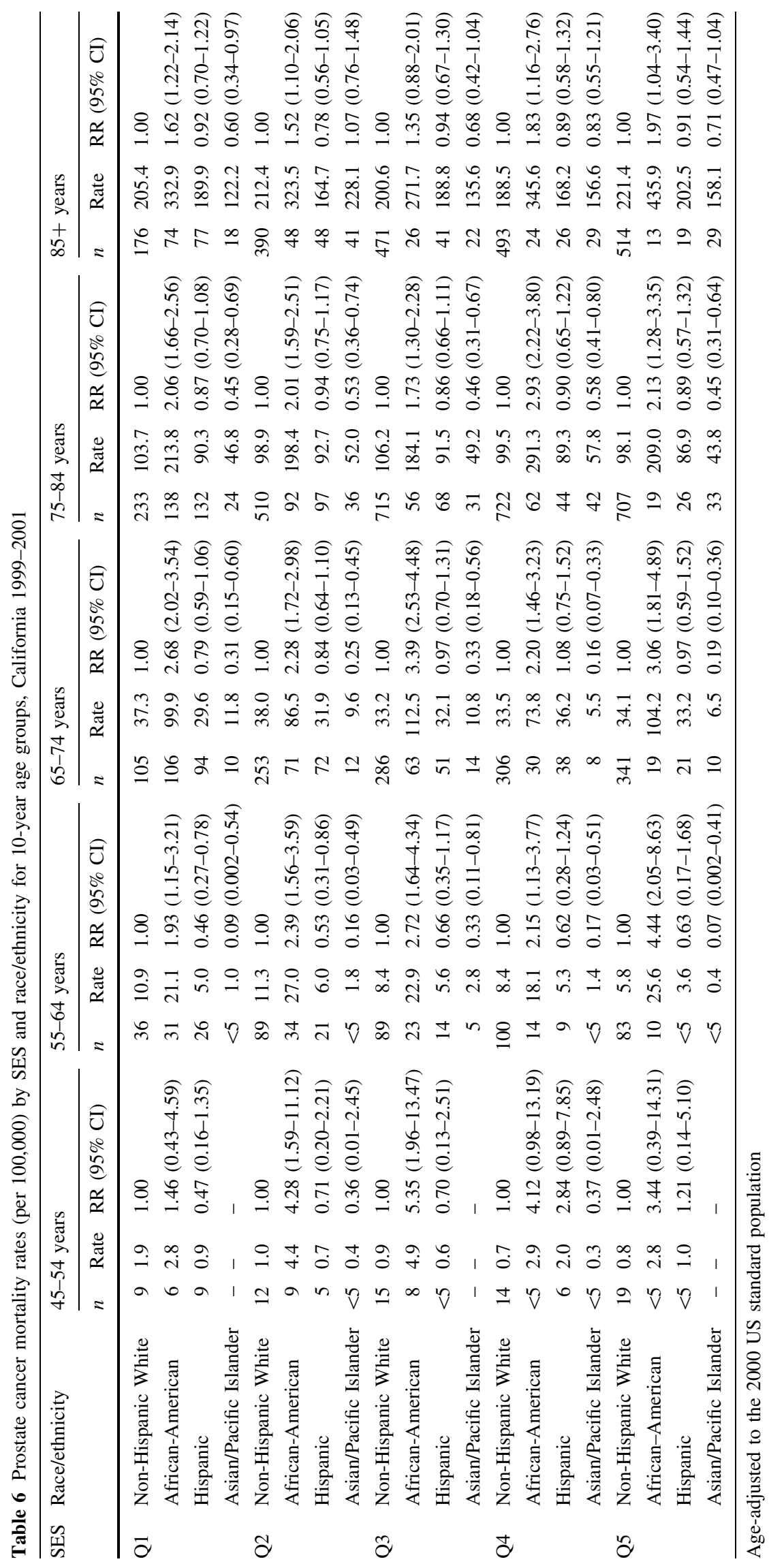


$[15,17,20]$. Similarly, in a multiethnic cohort study of African-Americans, Whites, and Asian-Americans, the disparity in prostate cancer survival and stage of presentation could not be eliminated by adjustment of SES and comorbidities [16]. We conducted a comparable survival analysis of men in our study diagnosed with prostate cancer from 1998 to 2002, adjusting for SES, stage, and grade; hazard ratios (HR) for prostate cancer death confirmed such disparity in risk: African-Americans $(\mathrm{HR}=1.20$; 95\% CI: 1.08-1.33), Asian/Pacific Islanders ( $\mathrm{HR}=0.59$; 95\% CI: 0.51-0.68), and Hispanics (HR $=0.89 ; 95 \% \mathrm{CI}$ : 0.81-0.98) when compared to non-Hispanic Whites.

Our findings suggest substantial influences of both innate and lifestyle factors in the differences in prostate cancer rates across groups. The consistent racial/ethnic disparity in incidence rates for all levels of SES among younger men (ages <55 years) indirectly support an important biological component to disease risk as early ages at diagnoses have been linked to biological contributors to disease. Exciting developments from recent genetic association studies, an admixture study of prostate cancer among African-Americans [28] and a multiethnic fine-mapping study [29], revealed a particular region on chromosome 8q24 that may contribute to the higher incidence of prostate cancer among African-Americans in comparison with non-Hispanic Whites. Compelling evidence provides strong support that genetic factors may account for at least part of racial/ethnic differences in disease. Lifestyle and contextual factors have yet to convincingly identify specific contributors; some studies have implicated dietary fat $[30,31]$, but the results are conflicting [32]. Regardless, our data suggest that the ongoing search for environmental causes of prostate cancer continues to be warranted.

Differences in treatment practices are an important consideration in evaluating racial/ethnic differences in prostate cancer mortality. Cancer registry data do not include detailed information regarding treatment, so we were unable to account for potential differences in treatment practices across racial/ethnic groups. Previous studies have reported that African-Americans are more likely to undergo less aggressive treatment than Whites [14, 33, 34], which may account for some of the observed differences in mortality. Recently, in a large California cancer registry study of differences in prostate cancer survival between African-Americans and Whites $(n=109,270)$, adjustment for stage and treatment eliminated most of the racial difference in survival; and with additional adjustment for SES, grade, and year of diagnosis, the survival difference between African-Americans and Whites was eliminated $(\mathrm{HR}=1.00 ; 95 \% \mathrm{CI}:$ 0.93-1.08) [13]. Although these findings indicate treatment differences are largely accountable for differences in survival, biological and environmental factors remain important contributors to racial/ethnic differences in the development of prostate cancer.

Our study has several limitations that warrant discussion. The use of a neighborhood-level index of SES is subjected to ecological fallacy such that incorrect inferences of individual levels of SES may have been made. In addition, by using overall census data to construct our index of SES, we may have overlooked factors that are particularly relevant for specific racial/ethnic groups. For example, Krieger et al. [35] report that for homes of equal value, African-Americans pay higher taxes in comparison with Whites, and for a given level of education, the economic returns are higher for Whites in comparison with African-Americans and Hispanics. This suggests that certain racial/ethnic groups at the same level of SES may not share the same level of power, prestige, and opportunities - variables that can capture these factors may improve SES measurement [22]. While we acknowledge SES may be measured with some error in our study, we have evidence that our index of SES is of sufficient quality to uncover important SES and cancer associations as seen in the literature (SES and breast cancer [22] and Hodgkinlymphoma [36]), providing certain confidence that our SES index is valid.

There are several strengths to this study. Foremost, this is the largest and most diverse study of prostate cancer disparities to date, having 98,000 incident prostate cancer cases and 9,000 prostate cancer deaths with substantial numbers of cases from four major racial/ethnic groups. In addition, as a population-based study our findings may be generalized to the diverse population of California at large. While our use of census data to derive an area measure of SES may not completely reflect data at the individual level, area-based measures have been suggested to capture elements of the socioeconomic environment that may not be obtainable by individual-level data [37].

In summary, the present study suggests that socioeconomic status alone does not appear to account for the differences in prostate cancer burden among AfricanAmericans, non-Hispanic Whites, Hispanics, and Asian/ Pacific Islanders. Large multiethnic studies with complementary individual- and area-level measures of SES are needed to corroborate our findings. The challenge remains to disentangle the complexities of racial/ethnic differences in screening, treatment, biological and environmental factors that contribute to differences in risk across groups. Such information will greatly aid the development of more targeted interventions to improve the social inequalities in prostate cancer incidence and mortality.

Acknowledgments This work is supported by the National Institute of Health R25T training grant (CA 112355-01A1). 
Open Access This article is distributed under the terms of the Creative Commons Attribution Noncommercial License which permits any noncommercial use, distribution, and reproduction in any medium, provided the original author(s) and source are credited.

\section{References}

1. American Cancer Society (2008) Cancer facts \& figures 2008. American Cancer Society, Atlanta

2. Ries LAG, Melbert D, Krapcho M, Stinchcomb DG, Howlader N, Horner MJ, Mariotto A, Miller BA, Feuer EJ, Altekruse SF, Lewis DR, Clegg L, Eisner MP, Reichman M, Edwards BK (eds) (2008) SEER Cancer Statistics Review, 1975-2005. http://seer cancergov/csr/1975_2005/, based on November 2007 SEER data submission, posted to the SEER web site

3. Adler NE, Newman K (2002) Socioeconomic disparities in health: pathways and policies. Health Aff (Millwood) 21:60-76

4. Krieger N (1991) Women and social class: a methodological study comparing individual, household, and census measures as predictors of black/white differences in reproductive history. $\mathbf{J}$ Epidemiol Community Health 45:35-42

5. Liu L, Cozen W, Bernstein L, Ross RK, Deapen D (2001) Changing relationship between socioeconomic status and prostate cancer incidence. J Natl Cancer Inst 93:705-709

6. Schwartz KL, Crossley-May H, Vigneau FD, Brown K, Banerjee M (2003) Race, socioeconomic status and stage at diagnosis for five common malignancies. Cancer Causes Control 14:761-766

7. Steenland K, Rodriguez C, Mondul A, Calle EE, Thun M (2004) Prostate cancer incidence and survival in relation to education (United States). Cancer Causes Control 15:939-945

8. Mackillop WJ, Zhang-Salomons J, Boyd CJ, Groome PA (2000) Associations between community income and cancer incidence in Canada and the United States. Cancer 89:901-912

9. Sanderson M, Coker AL, Perez A, Du XL, Peltz G, Fadden MK (2006) A multilevel analysis of socioeconomic status and prostate cancer risk. Ann Epidemiol 16:901-907

10. Krieger N, Quesenberry C Jr, Peng T et al (1999) Social class, race/ethnicity, and incidence of breast, cervix, colon, lung, and prostate cancer among Asian, Black, Hispanic, and White residents of the San Francisco Bay Area, 1988-92 (United States). Cancer Causes Control 10:525-537

11. Howe HL, Wu X, Ries LA et al (2006) Annual report to the nation on the status of cancer, 1975-2003, featuring cancer among U.S. Hispanic/Latino populations. Cancer 107:1711-1742

12. Robbins AS, Koppie TM, Gomez SL, Parikh-Patel A, Mills PK (2007) Differences in prognostic factors and survival among white and Asian men with prostate cancer, California, 19952004. Cancer 110:1255-1263

13. Robbins AS, Yin D, Parikh-Patel A (2007) Differences in prognostic factors and survival among White men and Black men with prostate cancer, California, 1995-2004. Am J Epidemiol 166:7178

14. Tewari A, Horninger W, Pelzer AE et al (2005) Factors contributing to the racial differences in prostate cancer mortality. BJU Int 96:1247-1252

15. Howard G, Anderson RT, Russell G, Howard VJ, Burke GL (2000) Race, socioeconomic status, and cause-specific mortality. Ann Epidemiol 10:214-223

16. Oakley-Girvan I, Kolonel LN, Gallagher RP, Wu AH, Felberg A, Whittemore AS (2003) Stage at diagnosis and survival in a multiethnic cohort of prostate cancer patients. Am J Public Health 93:1753-1759
17. Albano JD, Ward E, Jemal A et al (2007) Cancer mortality in the United States by education level and race. J Natl Cancer Inst 99:1384-1394

18. Oliver MN, Smith E, Siadaty M, Hauck FR, Pickle LW (2006) Spatial analysis of prostate cancer incidence and race in Virginia, 1990-1999. Am J Prev Med 30:S67-S76

19. Du XL, Fang S, Coker AL et al (2006) Racial disparity and socioeconomic status in association with survival in older men with local/regional stage prostate carcinoma: findings from a large community-based cohort. Cancer 106:1276-1285

20. Robbins AS, Whittemore AS, Thom DH (2000) Differences in socioeconomic status and survival among white and black men with prostate cancer. Am J Epidemiol 151:409-416

21. Dayal HH, Polissar L, Dahlberg S (1985) Race, socioeconomic status, and other prognostic factors for survival from prostate cancer. J Natl Cancer Inst 74:1001-1006

22. Yost K, Perkins C, Cohen R, Morris C, Wright W (2001) Socioeconomic status and breast cancer incidence in California for different race/ethnic groups. Cancer Causes Control 12:703-711

23. Liberatos P, Link BG, Kelsey JL (1988) The measurement of social class in epidemiology. Epidemiol Rev 10:87-121

24. Cook PJ, Doll R, Fellingham SA (1969) A mathematical model for the age distribution of cancer in man. Int $\mathrm{J}$ Cancer 4:93-112

25. Spencer BA, Babey SH, Etzioni DA et al (2006) A populationbased survey of prostate-specific antigen testing among California men at higher risk for prostate carcinoma. Cancer 106:765-774

26. Gilligan T, Wang PS, Levin R, Kantoff PW, Avorn J (2004) Racial differences in screening for prostate cancer in the elderly. Arch Intern Med 164:1858-1864

27. Bao Y, Fox SA, Escarce JJ (2007) Socioeconomic and racial/ ethnic differences in the discussion of cancer screening: "between-" versus "within-" physician differences. Health Serv Res 42:950-970

28. Freedman ML, Haiman CA, Patterson N et al (2006) Admixture mapping identifies $8 \mathrm{q} 24$ as a prostate cancer risk locus in African-American men. Proc Natl Acad Sci USA 103:14068-14073

29. Haiman CA, Patterson N, Freedman ML et al (2007) Multiple regions within 8q24 independently affect risk for prostate cancer. Nat Genet 39:638-644

30. Whittemore AS, Kolonel LN, Wu AH et al (1995) Prostate cancer in relation to diet, physical activity, and body size in blacks, whites, and Asians in the United States and Canada. J Natl Cancer Inst 87:652-661

31. Hayes RB, Ziegler RG, Gridley G et al (1999) Dietary factors and risks for prostate cancer among blacks and whites in the United States. Cancer Epidemiol Biomarkers Prev 8:25-34

32. Park SY, Murphy SP, Wilkens LR, Henderson BE, Kolonel LN (2007) Fat and meat intake and prostate cancer risk: the multiethnic cohort study. Int J Cancer 121:1339-1345

33. Sohayda CJ, Kupelian PA, Altsman KA, Klein EA (1999) Race as an independent predictor of outcome after treatment for localized prostate cancer. J Urol 162:1331-1336

34. Klabunde CN, Potosky AL, Harlan LC, Kramer BS (1998) Trends and black/white differences in treatment for nonmetastatic prostate cancer. Med Care 36:1337-1348

35. Krieger N, Williams DR, Moss NE (1997) Measuring social class in US public health research: concepts, methodologies, and guidelines. Annu Rev Public Health 18:341-378

36. Clarke CA, Glaser SL, Keegan TH, Stroup A (2005) Neighborhood socioeconomic status and Hodgkin's lymphoma incidence in California. Cancer Epidemiol Biomarkers Prev 14:1441-1447

37. Diez-Roux AV, Kiefe CI, Jacobs DR Jr et al (2001) Area characteristics and individual-level socioeconomic position indicators in three population-based epidemiologic studies. Ann Epidemiol 11:395-405 